BMJ Open Sport \& Exercise Medicine

\title{
Return to match running performance after a hamstring injury in elite football: a single-centre retrospective cohort study
}

Marloes I Hoppen (D) , ,2,3,4 Gustaaf Reurink, ${ }^{1,2,3}$ Vosse A de Boode, ${ }^{3}$ Lisanne van der Kaaden, ${ }^{3}$ Lotte Jagtman, ${ }^{3}$ Tim Glazenburg, ${ }^{3}$ Bastiaan Bruning, ${ }^{3}$ Johannes $\mathrm{L} \mathrm{Tol}{ }^{1,2,3,5}$

To cite: Hoppen Ml, Reurink G, de Boode VA, et al. Return to match running performance after a hamstring injury in elite football: a single-centre retrospective cohort study. BMJ Open Sport \& Exercise Medicine 2022;8:e001240. doi:10.1136/ bmjsem-2021-001240

- Additional supplemental material is published online only. To view, please visit the journal online (http://dx.doi. org/10.1136/bmjsem-2021001240).

Accepted 3 February 2022

Check for updates

\section{Author(s) (or their} employer(s)) 2022. Re-use permitted under CC BY-NC. No commercial re-use. See rights and permissions. Published by BMJ.

For numbered affiliations see end of article.

Correspondence to Johannes L Tol;

j.l.tol@amsterdamumc.nl

\section{ABSTRACT}

Objectives To determine the number of matches to return to pre-injury match running performance after sustaining an acute hamstring injury.

Methods In this retrospective cohort study, the injuries of the players of the first, Under21, Under19, Under18 and Under17 teams of a professional football club in the period 2017-2020 were analysed. Acute hamstring injuries with a minimal absence from training or match play of 7 days were included. For running performance, we assessed the following variables: maximal velocity ( $\mathrm{km} / \mathrm{hour})$, total distance, high-intensity distance (17.5-22.5 km/hour) and sprint distance ( $>22.5 \mathrm{~km} /$ hour). We calculated the average and $95 \% \mathrm{Cl}$ for these variables during the last five matches before the injury. The primary outcome was the number of matches to reach maximal velocity within the $95 \% \mathrm{Cl}$ of the player's individual pre-injury performance. Secondary outcome scores included the duration (in days and matches) to reach the other running performance variables.

Results 18 hamstring injuries in 15 players were included. 15 out of 18 injuries (83\%) showed a return to pre-injury maximal velocity in the second match after return to play. The median number of matches to return to pre-injury maximal velocity was 2 (IQR 1-2). In the first match after return to play, pre-injury total distance was reached in $100 \%$ of the injuries, pre-injury sprint distance was reached in $94 \%$ of the injuries and pre-injury highintensity distance was reached in $89 \%$ of the injuries. Conclusion Following an acute hamstring injury in elite football, pre-injury match running performance is reached in the first or second match.

\section{INTRODUCTION}

Acute muscle injuries of the lower extremity are the most common injury in elite football, representing about one-third of all time-loss injuries. ${ }^{1}$ In particular, hamstring injuries are the single most common injury in elite football, accounting for 5\%-15\% of all football-related injuries. Time-loss due to a hamstring injury varies from days to several months. Reported re-injury

\section{Key messages}

What is already known on this topic

- Hamstring injuries are the most common injury in elite football.

- Match running performance is impaired after returning to play from an acute hamstring injury.

\section{What this study adds}

- Within two matches after return to play, $83 \%$ of the players with a hamstring injury returned to preinjury maximal velocity levels.

- In the first match after return to play, $100 \%$ of the players with a hamstring injury reached their preinjury total distance, $94 \%$ reached their pre-injury sprint distance, $89 \%$ reached their pre-injury highintensity distance and $50 \%$ reached their pre-injury maximal velocity.

How this study might affect research, practice or policy

- Future studies might evaluate potential factors associated with a quick return to pre-injury match running performance after a hamstring injury.

rates of hamstring injuries vary between $4 \%-68 \% .^{2}$ Re-injuries cause significantly longer absences than index injuries. ${ }^{13}$ The economic burden of an elite soccer player being absent for 1 month is estimated to be $€ 500$ 000. ${ }^{4}$ Moreover, a lower player availability in elite soccer teams was associated with a lower final league ranking and a decreased average points gained per league match. ${ }^{5}$ Therefore, the goal of the post-injury rehabilitation is twofold: a quick return to their pre-injury performance level with minimal risk of re-injury.

In the international consensus statement on return to play criteria after a hamstring injury, four return-to-play phases are distinguished: return to run, return to train, return to play and return to performance. ${ }^{6-8}$ 
Research has predominantly focused on treatment protocols and progression criteria in the early stages of the continuum until return to play. Research on return to performance is limited. ${ }^{9}$ Training and match load performance were the most commonly used criteria for returning to performance after a hamstring injury by premier league soccer clubs. ${ }^{9}$

Only three studies have evaluated the return to running performance after a hamstring injury. ${ }^{10-12}$ Running performance parameters that were studied were maximal and average velocity, distance ran at high, very high and sprint intensity and the work-torest ratio (distance covered $>7 \mathrm{~km} /$ hour / distance covered $<7 \mathrm{~km} /$ hour). Two of these studies report an impaired performance after return to play, namely a reduction in maximal velocity during a $50 \mathrm{~m}$ sprint test up to 2 months after return to play ${ }^{12}$ and a decrease in high-intensity distance ran up to 15 matches after return to play. ${ }^{11}$ However, in Spanish semi-elite soccer players, likely improvements were reported for all match load parameters at the moment of return to play and $6-10$ weeks after return to play compared with preinjury performance. ${ }^{10}$

Due to the limited number of studies on return to performance, it remains unclear whether running performance can be expected to return to the preinjury level after a hamstring injury and how long it takes for players to return to their pre-injury performance level. Therefore, this study aims to determine the duration in matches and days to return to pre-injury maximal velocity, total distance, high-intensity distance and sprint distance after sustaining an acute hamstring injury.

\section{METHODS AND PROCEDURES \\ Research design and participants}

This is a retrospective cohort study. The players of the male first team, Under21 (U21), Under19 (U19), Under18 (U18) and Under17 (U17) team during the seasons 2017-2018, 2018-2019 and 2019-2020 of a Dutch premier league club participated in the study. All players gave written informed consent before the start of the data collection. This retrospective study on usual clinical care was not considered subject to the Dutch Medical Research Involving Human Subjects Act (Wet Medisch wetenschappelijk Onderzoek met mensen). The study was conducted according to the recommendations of the Declaration of Helsinki. During these seasons, players with hamstring injuries were identified in the standardised medical database (Smartabase 2020, Fusion Sport, Australia).

\section{Eligibility criteria}

We included time-loss injuries when they were clinically diagnosed with an acute muscle injury of the posterior thigh with an absence from training or competition of at least 7 days. To prevent the reuse of pre-injury performance data, we excluded early re-injuries of these players. Early re-injuries were defined as 'an injury of the same type and at the same site as an index injury and which occurs within 2 months after a player's return to full participation from the index injury', according to the definition of Fuller et $a l^{13}$ (pg. 84). Players were excluded when the running performance data of the player was not representable due to measurement errors or unavailable 6 months before the injury or 6 months after return to play.

\section{Patient and public involvement}

Players and the public were not involved in our study's the design, conduct or reporting plans.

\section{Data collection}

The movement of all players was measured during all competitive matches. Three different tracking systems were used for the match running performance data collection. The match running performance of the first team was derived by optical tracking of the video data of the match using a Local Positioning System (LPS) (Inmotio Object Tracking, $45 \mathrm{~Hz}$, Amsterdam, The Netherlands). The U21 and U18 teams usually played their matches using a LPS (Inmotio Object Tracking, $45 \mathrm{~Hz}$ ). If playing with the LPS was impossible for practical reasons, a Global Positioning System (GPS) (Catapult Sports, Vector $10 \mathrm{~Hz}$, Melbourne, Australia) was used to obtain running performance data.

The LPS and $10 \mathrm{~Hz}$ GPS systems have been validated to measure distance and maximal velocity in team sports. Compared with radar measurements, reported SEs of estimates vary from $2 \%-10 \%$, depending on the system used, the task performed and the variable studied. ${ }^{14-19}$ An overview of the recent literature studying the validity of (comparable) LPS and GPS systems can be found in the online supplemental tables S1 and S2. We used the standard software of the three tracker systems to extract the GPS or LPS data.

\section{Study measures}

\section{Running performance parameters}

The running performance parameters that we studied are maximal sprinting velocity $(\mathrm{km} /$ hour $)$, relative total distance covered, relative distance covered at high-speed running ( $>17.5 \mathrm{~km} /$ hour to $22.5 \mathrm{~km} /$ hour) and relative distance covered at sprint-speed running $(>22.5 \mathrm{~km} /$ hour). All distance variables are related to the total minutes of playing time during the match and expressed in $\mathrm{m} / \mathrm{min}$.

\section{Pre-injury running performance}

We determined the pre-injury running performance level based on the last five matches before injury occurrence, in which a minimum of $45 \mathrm{~min}$ was played. We measured the maximal sprinting velocity and average total distance, average high-speed running distance and average sprintspeed running distance of the last five matches as the pre-injury performance level. As there is considerable variance in running performance between matches due 


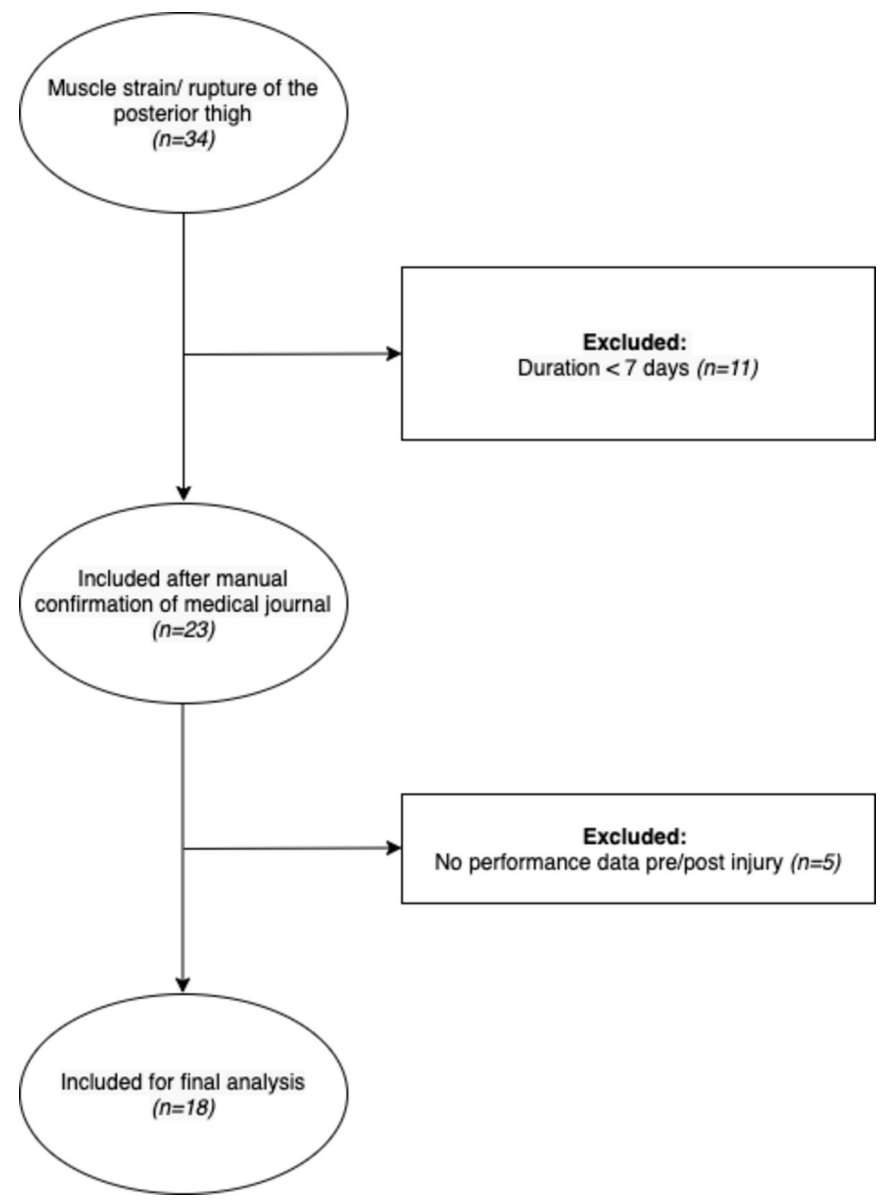

Figure 1 Flow chart of the included injuries.

to differences in opponents, playing positions and playing duration, ${ }^{20}$ a $95 \%$ CI of the pre-injury performance level was determined for each individual injury record.

Return to play

The moment of return to play was defined as the date a player achieved clearance by the medical staff to join the team training and matches without restrictions. The date of return to play and the corresponding duration of absence (in days) was manually confirmed by checking the medical file.

\section{Return to running performance}

To determine the moment of return to performance, we analysed all matches in 6 months after return to play, in which the player played at least $45 \mathrm{~min}$. The first match in which the player achieved the pre-injury running performance level within the $95 \% \mathrm{CI}$ is defined as the date of return to performance. An example of the maximal velocity reached pre-injury and post-injury of an individual player, including the pre-injury performance level and lower bound of the $95 \% \mathrm{CI}$, can be found in the online supplemental figure S1.

\section{Primary and secondary outcome measures}

The primary outcome measure of our study is the number of matches until pre-injury maximal velocity was reached.
Table 1 Player and injury characteristics of the included injuries

\begin{tabular}{lll}
\hline Player characteristics & $\begin{array}{l}\text { Number of } \\
\text { injuries }\end{array}$ \\
\hline Mean age (years) & $20.89(\mathrm{SD}=3.41)$ & \\
Team & First team & 10 \\
& Under21 & 4 \\
& Under19 & 4 \\
& Under18 & 0 \\
& Under17 & 0 \\
Injury characteristics & & \\
Median injury duration of & 14 (IQR=11-26) \\
absence (days) & & \\
\hline
\end{tabular}

The secondary outcome measures were (1) the number of matches until total distance, high-intensity distance and sprint distance were reached and (2) the number of days after return to play until pre-injury maximal velocity, total distance, high-intensity distance and sprint distance were reached.

\section{Sample size}

We did not perform an a priori sample size calculation for this study. Instead, we used all hamstring injuries registered in the medical database from 1 June 2017 until 1 July 2020 to obtain a convenience sample size.

\section{Statistical analysis}

The medical and running performance variables will be presented using descriptive statistics. The data analysis is performed in R, using RStudio (V.1.3.1093, RStudio PBC). Statistical analysis is performed using SPSS Statistics (V.24).

\section{RESULTS}

\section{Included injuries}

We included a total of 18 hamstring injuries in 15 players in the final analysis. Figure 1 shows a flow chart of the included injuries.

\section{Injury and player characteristics}

Injuries of 15 different players were included in the study. Two players had multiple included injuries, concerning five injuries. One of these players had a hamstring injury at the same side 9 months apart. The other player had a hamstring injury on the right side, and 2 years later, he sustained two hamstring injuries on the left side 6 months apart. The player and injury characteristics are presented in table 1.

\section{Return to pre-injury running performance}

In the 6 months after return to play a median of 13 matches (IQR 7-18) per injury was analysed for return to performance. Players participated in a median of 0 (IQR $0-1$ ) matches for less than $45 \mathrm{~min}$ between the moment 


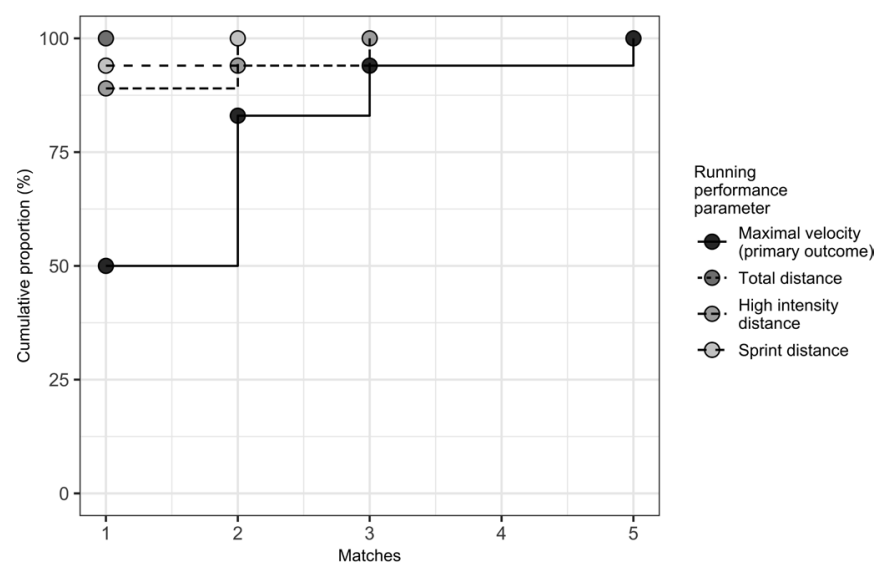

Figure 2 The cumulative proportion (\%) of the included injuries reaching pre-injury performance level for each match after return to play. The four running performance parameters are presented: Maximal velocity (solid line), total distance (dotted line), high-intensity distance (double dashed line) and sprint distance (dashed line).

of return to play and the first match in which they played longer than $45 \mathrm{~min}$.

\section{Primary outcome: return to maximal velocity in number of matches}

In all injuries, pre-injury maximal velocity was reached within 6 months after returning to play. The median number of matches for reaching pre-injury maximal velocity was 2 (IQR 1-2) (see figure 3A). In 9 (50\%) injuries, pre-injury maximal velocity was reached in the first match after return to play. In 15 (83\%) injuries, pre-injury maximal velocity was reached within two matches, and in 17 (94\%) injuries within the third match (see figure 2).

Secondary outcomes: return to total distance, high-intensity distance and sprint distance in number of matches

After returning to play, pre-injury total distance was reached within one match in all injuries. Return to pre-injury sprint distance occurred in 17 (94\%) injuries in the first match (see figure 2). Return to pre-injury high-intensity distance occurred in $16(89 \%)$ injuries in the first match and 17 $(94 \%)$ injuries in the second match. For total distance, highintensity distance and sprint distance, the median match for reaching pre-injury performance was 1 (IQR 1-1) match for all three parameters (see figure $3 \mathrm{~A}$ ).

\section{Secondary outcome: return to running performance in several days}

The median number of days to reach the pre-injury maximal velocity was 11 (IQR 4-23) days. The median number of days for reaching pre-injury total distance, high-intensity distance and sprint distance covered were 5 (IQR 3-10), 5 (IQR 4-11) and 5 (IQR 3-10) days, respectively (see figure 3B).

\section{DISCUSSION}

Following hamstring injuries in elite football, return to maximal match running velocity can be expected to be reached in the first match in half of the injuries and within two matches in 4 out of 5 injuries. Total distance, high-intensity distance and sprint distance were reached in at least 9 out of 10 injuries in the first match after return to play.

Compared with recent literature on return to performance after hamstring injuries, the relatively high proportion of early return to pre-injury performance level is quicker than in two previous studies. A persisting decline in high-intensity distance ran during matches by half of the players after a hamstring injury was reported in a population of professional football, Rugby League and Australian Rules football. ${ }^{11}$ The decline in the high-intensity distance was visible until 15 matches after return to play. Their study did not include more than 15 matches after return to play. It remains unclear whether these players eventually return to their pre-injury performance after a longer period. The delay in return to performance in their
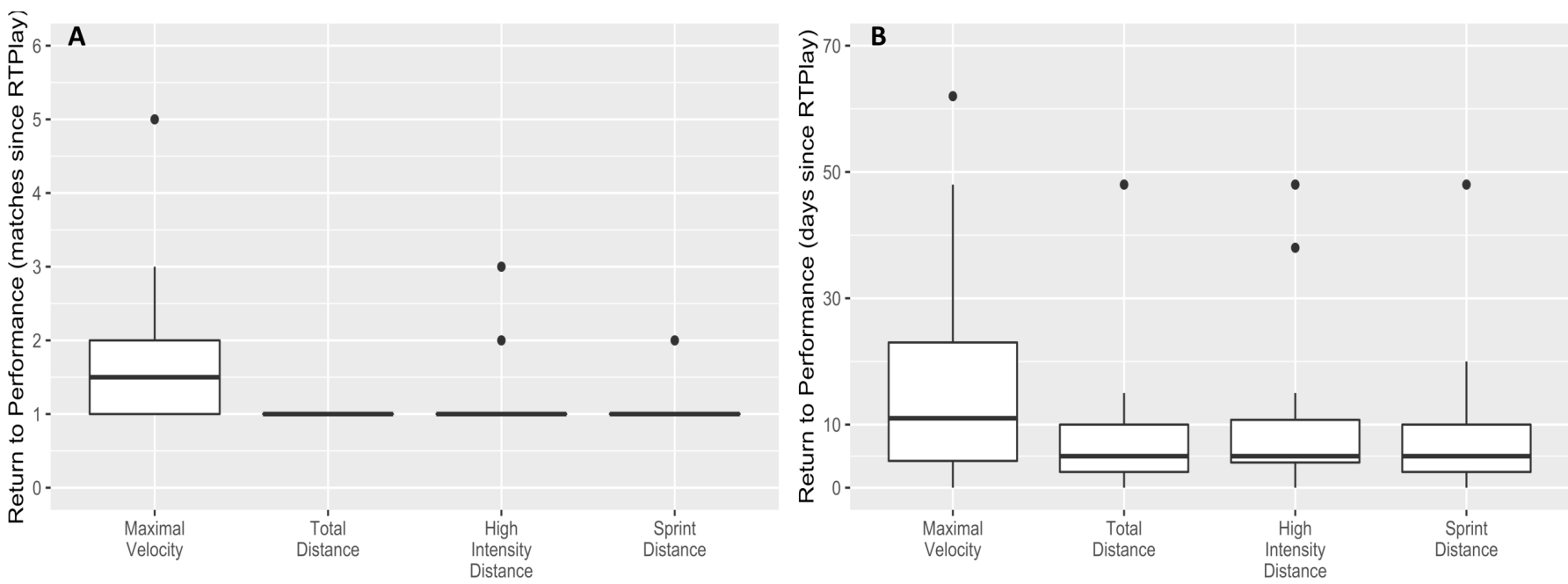

Running performance parameter

Figure 3 Boxplots representing the median and IQR of the number of matches $(A)$ and the number of days (B) from the return to play until the pre-injury performance level was reached. RTPlay, return to play. 
study compared with the results of our study can be explained by both the different study populations and the different methods of analysis.

A lower maximal velocity was reported during a $50 \mathrm{~m}$ maximal sprint test, even 2 months after returning to play, in semi-elite football players. ${ }^{12}$ As they studied single maximal sprint performance, the results of our study may be more informative on the ability of the player to perform repeated sprints and their performance during matches. Our study shows comparable results as a study that included elite Spanish football players. ${ }^{10}$ Their study showed likely improvements compared with pre-injury performance in maximal velocity and distance ran at high, very high and sprint intensity in the first match after medical clearance (return to play) and 6-10 weeks after return to play.

\section{Methodological limitations}

The use of the lower bound of the $95 \%$ CI as a cutoff value for reaching pre-injury performance may not be sensitive enough to detect smaller running performance deficits after a hamstring injury. However, we decided to use this CI to compensate for the considerable variance in running performance between the five matches before the injury due to differences in opponents, playing positions and playing duration. ${ }^{20}$ In general, more research on finding robust measures of defining performance in soccer is necessary. Possibly relating an individual's performance to the team average would reduce the match-to-match variability in performance measures, and performance deficits can be detected more accurately. The validity of the GPS and LPS systems has mostly been studied during small-sided games instead of actual gameplay. Therefore, the measurement error of these systems during an actual football match remains unclear. ${ }^{1416}$ Additionally, the two tracking systems are used interchangeably in this study. At the same time, research shows that a correction factor of the specific setting is necessary to directly compare measurements of the different systems for accurate use of the two systems. ${ }^{14}$ Still, the individual 95\% CI used in our study has a broader range than the measurement error reported in validity studies. ${ }^{14} 16$

We have included match play longer than $45 \mathrm{~min}$. This is a potential confounder because a return to performance may occur in earlier matches in which less than $45 \mathrm{~min}$ is played. However, our results report that most of our cohort did not participate in any matches for less than $45 \mathrm{~min}$ before the first analysed match. Another potential confounding factor is that a coach may decide not to line up a player after medical clearance (return to play). This would increase the length of the return to play-return to performance interval in days but does not imply that a performance deficit is present. That data was collected at a single football club limits the generalisability to other clubs or sports settings. Because this was a retrospective study, the rehabilitation protocol and progression criteria were not standardised. Bias may occur due to the inclusion of multiple injuries of similar players, and our sample was not completely independent.

\section{Clinical application and future research}

Our study implies that elite football players can return to match play from a hamstring injury at their pre-injury running performance level within their first or second match after injury. Future studies might evaluate these performance parameters during the final stages of rehabilitation and the team training sessions before first match participation. This could detect potential factors associated with return running performance after injury to guide the return to performance process.

\section{CONCLUSION}

After hamstring injuries in elite football return to pre-injury maximal velocity during matches can be reached within two matches after return to play. Total distance, high-intensity distance and sprint distance covered during matches returned to pre-injury levels in the first match after return to play.

\section{Author affiliations}

${ }^{1}$ Academic Centre for Evidence-based Sports Medicine (ACES), University of Amsterdam, Amsterdam UMC Locatie AMC, Amsterdam, The Netherlands ${ }^{2}$ Amsterdam Collaboration on Health \& Safety in Sports (ACHSS), Amsterdam UMC Locatie AMC, Amsterdam, The Netherlands

${ }^{3}$ Medical-Performance-Science Department, AFC Ajax, Amsterdam, The Netherlands ${ }^{4}$ Department of Human Movement Sciences, Vrije Universiteit Amsterdam, Amsterdam Movement Sciences, Amsterdam, The Netherlands

${ }^{5}$ Aspetar Orthopaedic and Sports Medicine Hospital, Doha, Qatar

Acknowledgements We wish to thank the players, performance and science staff of AFC Ajax for their participation, collaboration and support in executing this study.

Contributors MIH, JLT, GR, TG and BB: Conception and design of the work. MIH, VAdB, LvdK and LJ: Acquisition of data. MIH, JLT, GR, VAdB, LvdK and LJ: Analysis and interpretation of the data. MIH drafted the manuscript. All authors revised the manuscript for important intellectual content and gave their approval to publish the final version of the manuscript. MIH is acting as the guarantor of the work.

Funding The authors have not declared a specific grant for this research from any funding agency in the public, commercial or not-for-profit sectors.

Competing interests None declared.

Patient and public involvement Patients and/or the public were not involved in the design, or conduct, or reporting, or dissemination plans of this research.

Patient consent for publication Not applicable.

Ethics approval As this was a retrospective study on usual clinical care, it was not considered subject to the Dutch Medical Research Involving Human Subjects Act (Wet Medisch wetenschappelijk Onderzoek met mensen). Participants gave informed consent to participate in the study before taking part.

Provenance and peer review Not commissioned; externally peer reviewed.

Data availability statement Data are available upon reasonable request.

Open access This is an open access article distributed in accordance with the Creative Commons Attribution Non Commercial (CC BY-NC 4.0) license, which permits others to distribute, remix, adapt, build upon this work non-commercially, and license their derivative works on different terms, provided the original work is properly cited, appropriate credit is given, any changes made indicated, and the use is non-commercial. See: http://creativecommons.org/licenses/by-nc/4.0/.

\section{ORCID iD}

Marloes I Hoppen http://orcid.org/0000-0003-3604-1982 


\section{REFERENCES}

1 Ekstrand J, Hägglund M, Waldén M. Injury incidence and injury patterns in professional football: the UEFA injury study. $\mathrm{Br} J$ Sports Med 2011;45:553-8.

2 Diemer WM, Winters M, Tol JL, et al. Incidence of acute hamstring injuries in soccer: a systematic review of 13 studies involving more than 3800 athletes with 2 million sport exposure hours. J Orthop Sports Phys Ther 2021;51:27-36.

3 Stubbe JH, van Beijsterveldt A-MMC, van der Knaap S, et al. Injuries in professional male soccer players in the Netherlands: a prospective cohort study. J Athl Train 2015;50:211-6.

4 Ekstrand J. Keeping your top players on the pitch: the key to football medicine at a professional level. Br J Sports Med 2013;47:723-4.

5 Hägglund M, Waldén M, Magnusson $\mathrm{H}$, et al. Injuries affect team performance negatively in professional football: an 11-year followup of the UEFA champions League injury study. Br J Sports Med 2013;47:738-42.

6 van der Horst N, Backx F, Goedhart EA, et al. Return to play after hamstring injuries in football (soccer): a worldwide Delphi procedure regarding definition, medical criteria and decision-making. $\mathrm{Br} \mathrm{J}$ Sports Med 2017;51:1583-91.

7 Zambaldi M, Beasley I, Rushton A. Return to play criteria after hamstring muscle injury in professional football: a Delphi consensus study. Br J Sports Med 2017;51:1221-6.

8 Ardern CL, Glasgow P, Schneiders A, et al. 2016 consensus statement on return to sport from the first world Congress in sports physical therapy, Bern. Br J Sports Med 2016;50:853-64.

9 Dunlop G, Ardern CL, Andersen TE, et al. Return-to-Play practices following hamstring injury: a worldwide survey of 131 premier League football teams. Sports Med 2020;50:829-40.

10 Jiménez-Rubio S, Navandar A, Rivilla-García J, et al. Improvements in Match-Related physical performance of professional soccer players after the application of an on-Field training program for hamstring injury rehabilitation. J Sport Rehabil 2020;29:1145-50.
11 Whiteley R, Massey A, Gabbett T, et al. Match high-speed running distances are often suppressed after return from hamstring strain injury in professional footballers. Sports Health 2021;13:290-5.

12 Mendiguchia J, Samozino P, Martinez-Ruiz E, et al. Progression of mechanical properties during on-field sprint running after returning to sports from a hamstring muscle injury in soccer players. Int $\mathrm{J}$ Sports Med 2014;35:690-5.

13 Fuller CW, Ekstrand J, Junge A, et al. Consensus statement on injury definitions and data collection procedures in studies of football (soccer) injuries. Scand J Med Sci Sports 2006;16:83-92.

14 Buchheit M, Allen A, Poon TK, et al. Integrating different tracking systems in football: multiple camera semi-automatic system, local position measurement and GPs technologies. J Sports Sci 2014;32:1844-57.

15 Linke D, Link D, Lames M. Validation of electronic performance and tracking systems EPTS under field conditions. PLoS One 2018;13:e0199519-19.

16 Stevens T GA, de Ruiter CJ, van Niel C, et al. Measuring acceleration and deceleration in soccer-specific movements using a local position measurement (LPM) system. Int J Sports Physiol Perform 2014:9:446-56.

17 Lacome M, Peeters A, Mathieu B, et al. Can we use GPs for assessing sprinting performance in rugby sevens? A concurrent validity and between-device reliability study. Biol Sport 2019;36:25-9.

18 Hoppe MW, Baumgart C, Polglaze T, et al. Validity and reliability of GPs and LPS for measuring distances covered and sprint mechanical properties in team sports. PLoS One 2018;13:e0192708-21.

19 Rampinini E, Alberti G, Fiorenza M, et al. Accuracy of GPs devices for measuring high-intensity running in field-based team sports. Int $J$ Sports Med 2015;36:49-53.

20 Rivilla-García J, Calvo LC, Jiménez-Rubio S, et al. Characteristics of very high intensity runs of soccer players in relation to their playing position and playing half in the 2013-14 Spanish La LigA season. $J$ Hum Kinet 2019;66:213-22. 